\title{
Influence of the binder technological shrinkage on the strength of composite reinforcement
}

\author{
Vladimir Barsukov ${ }^{1}$, Alla Volik $^{1}$, and Sviatlana Sazon ${ }^{1}$ \\ ${ }^{1}$ Yanka Kupala State University of Grodno, 230023 Grodno, 22 Ozheshko str., Belarus
}

\begin{abstract}
A structural and mechanical analysis of the effect of polymer binder technological shrinkage on the destruction mechanisms and strength at break of construction composite reinforcement has been carried out. Using the results of our own experimental studies, as well as published data of other researchers, the differences in the destruction mechanisms of fiberglass and carbon fiber reinforcement are shown. A calculated assessment of the polymer shrinkage effect in the anchor sleeve on the appearance of additional shrinkage stresses in the interface between the reinforcement bar and the test anchor sleeve has been made. The results obtained make it possible to modernize the methodology for predictive assessment of the strength of composite construction reinforcement and can be used by engineering and technical workers of manufacturers and consumers of such reinforcement, as well as in the educational process in the preparation of engineering personnel for the construction profile.
\end{abstract}

\section{Introduction}

When working under conditions of exposure to moisture and other corrosive environments composite reinforcement is in many cases more effective than traditional metal. In many scientific and research and production - research centers of the Republic of Belarus $[1-6]$, the Russian Federation [7 - 9] and other countries [10 - 20] research and development are carried out aimed at creating a modernization of the structure, manufacturing technology and test methods of construction composite reinforcement not only on the basis of the most economical and already traditional glass and basalt fibers [12 - 14]. Hybrid composites are also being created which additionally include along with glass, carbon, aramid, or metal fibers [10, 15-23]. However despite the progress made many issues affecting the strength of products are insufficiently studied which is the main constraining factor in the establishment of scientifically based standards for assigning mechanical characteristics, control and testing methods $[7,8]$.

One of these insufficiently studied factors is the polymer binder thermal and chemical shrinkage during its curing as a result of which the composite components are pre-stressed and the fibers are pre-compressed in radial and axial directions, and the resin (binder, matrix) is stretched. A number of works are devoted to the analysis of shrinkage stresses in polymer 
composites $[24,25]$. However this factor has not been adequately studied in relation to composite building reinforcement.

Also the shrinkage effect of the polymer poured into the anchor sleeves on the features of the stress-strain state of those tested in accordance with the standards in force in the Republic of Belarus and the Russian Federation for testing construction composite reinforcement has not been studied.

The aim of the study is to develop techniques and implement with their help the structural and mechanical analysis of the polymer binders shrinkage effect on the destruction mechanisms and strength at break of construction composite reinforcement.

\section{Method}

Investigations of the regularities the construction composite reinforcement destruction at rupture were carried out in two mutually complementary directions. At the first stage a structural and mechanical analysis of the factors contributing to a decrease in the strength of real composites in comparison with the ideal ones described using the "rule of mixtures" was carried out. At the same time the effect of polymer resins shrinkage during curing on the appearance of shrinkage stresses in reinforcing fibers and polymer binder and the effect of these stresses on the fracture mechanism during tensile tests of building composite reinforcement were simulated. In the structural and mechanical analysis the hypothesis of plane sections was accepted according to which the deformations of the fibers and the binder are equal at the time of the composite destruction. Therefore for the relationship between the fracture stresses in the matrix $\sigma_{b m}$ and deformations $\varepsilon_{b m}$ we took

$$
\varepsilon_{b m}=\frac{\sigma_{f}}{E_{f}}=\frac{\sigma_{b m}}{E_{m}}
$$

where $E_{f}$ and $\mathrm{E}_{\mathrm{m}}$ - the elastic moduli of the fibers and the cured resin (binder) respectively.

The stresses $\sigma_{\mathrm{ct}}$ in the composite at the time of the binder initial destruction with the subsequent destruction of the fibers based on the results of the structural-mechanical analysis were described by the following dependence

$$
\sigma_{c t}=\sigma_{f} \theta_{f}+\sigma_{b m}\left(1-\theta_{f}\right)=\varepsilon_{b m}\left(E_{f} \theta_{f}+E_{m} \theta_{m}\right)
$$

where $\theta_{f}$ and $\theta_{m}$ are the volume of fibers and cured resin (binder), respectively.

The second direction covered the influence for the polymer resin poured into the anchor sleeves technological shrinkage during tensile tests in accordance with GOST 12004 on the features of the stress-strain state of the interface between the composite reinforcement bar and the hardened polymer cylinder inside the anchor sleeve.

Mating the reinforcement bar with a hardened resin cylinder inside the anchor sleeve was considered as an interference fit in which contact shrinkage pressures $\mathrm{P}$ act on the reinforcement bar and the sleeve (Figure 1). For an approximate analysis of the stress-strain state an analytical dependences based on the Lamé formula were used. In this case the elastic modulus of the cured polymer $\mathrm{E}_{\mathrm{p}}$ was taken as the elastic modulus of the sleeve and the transversal elastic modulus of the rod $\mathrm{E}_{\mathrm{tb}}$ was calculated using the formulas of the structural mechanics of composites [11]

$$
\frac{1}{E_{t b}}=\frac{\theta_{m}}{E_{m}}+\frac{\theta_{f}}{E_{f}}
$$




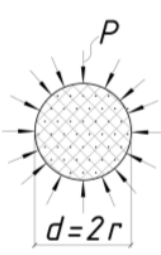

a)

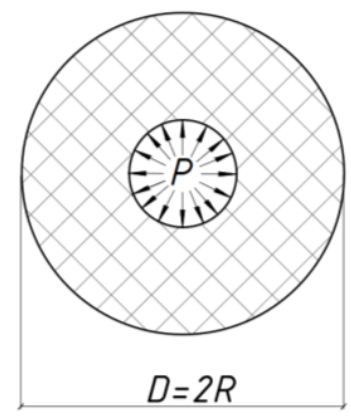

b)

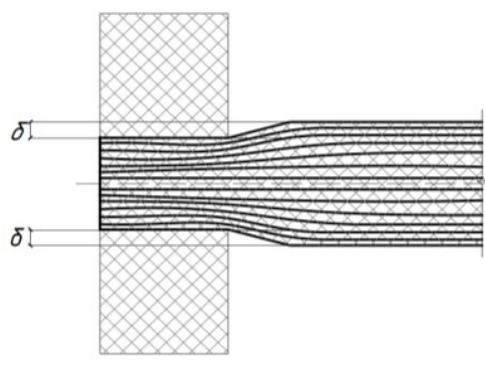

c)

1 - metal shell of the anchor sleeve, 2 - polymer sleeve made of hardened resin, 3 -composite reinforcement bar.

Fig. 1 - Scheme of the loads acting on the reinforcement bar (a), the polymer cylinder inside the anchor sleeve (b) and the deformations of the bar from shrinkage of the polymer resin inside the anchor sleeve (c)

Since methods for calculating the magnitude of the reduction in residual deformations due to the binder shrinkage have not been developed acceptable for engineering purposes this problem was assessed from a different standpoint by measuring of the composite deformation before fracture.

Experimental studies were carried out in accordance with GOST 12004 on a tensile testing machine MI 5047-50-11 with the fulfillment of the requirements for a reinforcement gripper. In addition for the theoretical analysis of the destruction mechanisms the experimental data of other researchers published in the scientific and technical literature were also used.

\section{Research results and discussion}

The structural and mechanical analysis is based on the results of comparing the indicators of the deformation and strength properties of reinforcing fibers and polymer resins commonly used in the production of monofibrillar and hybrid composites. The values presented in Table 1 were obtained as a result of processing the data presented in the scientific and technical literature $[10,11,22-25]$ as well as in Internet sources on the websites of manufacturers.

The performed analysis allows us to consider two fundamentally different of destruction mechanisms for construction composite reinforcement as possible. The first mechanism which is the basis on the widely used "rule of mixtures" involves the initial destruction of the reinforcing fibers as more fragile in comparison with the polymer binder. Such a mechanism is beyond doubt for composites using carbon fibers (deformation to fracture $0,3-0,45 \%$ ) and is confirmed by micrographs of fractured samples [28].

At the same time in the technical recommendations on the use for non-metallic composite reinforcement with a periodic profile in concrete structures (TR 013-1-04, Moscow, 2004) it is determined that the deformation upon rupture of fiberglass reinforcement with a nominal diameter of $5 ; 8$ and $10 \mathrm{~mm}$ is $2,3 \%$ and does not depend on the diameter of the reinforcement. For basalt-plastic reinforcement of the same nominal diameters the deformation at break was $2,5 \%$ and also does not depend on the reinforcement diameter. In addition the standard of Belarus STB 1103-98 "Fiberglass reinforcement" which applies to fiberglass reinforcement with a diameter of $6 \mathrm{~mm}$ provides for a similar value of controlled elongation $-2,7 \%$. Similar results were obtained by the authors of the article when testing Belarusian-made fiberglass 
reinforcement. Comparison of these values $(2,3-2,7 \%)$ with the values of the fracture strains of glass and basalt fibers given in Table 1 shows that for reinforcing fibers with increased strain at break the initial destruction of the binder (matrix) is possible if the strength of the fibers is not completely exhausted. This mechanism is supported by the so-called "whisk" effect from reinforcing fibers which was observed both in experiments [5] conducted by the authors of this work (Figure 2) and in publications of other researchers [25, 29].

Table 1. Properties of reinforcing fibers and polymer binders for the production of construction composite reinforcement

\begin{tabular}{|c|c|c|c|c|}
\hline Material & $\begin{array}{l}\text { Density, } \\
\text { kg / m3 }\end{array}$ & $\begin{array}{c}\text { Elastic } \\
\text { modulus, GPa }\end{array}$ & $\begin{array}{c}\text { Tensile } \\
\text { strength, MPa }\end{array}$ & $\begin{array}{l}\text { Breaking } \\
\text { strain,\% }\end{array}$ \\
\hline \multicolumn{5}{|c|}{ Fiber } \\
\hline \multirow[t]{2}{*}{ Glass type E } & 2570 & 72.5 & $3300-3500$ & $4.5-4.8$ \\
\hline & 2560 & 73 & 3330 & 4.4 \\
\hline \multirow[t]{2}{*}{ Glass type S } & 2470 & 88 & 4600 & $3.0-5.2$ \\
\hline & 2540 & 87 & 4300 & 4.9 \\
\hline Basalt & 2670 & $70-90$ & $2700-3500$ & $3.0-3.9$ \\
\hline \multirow{2}{*}{$\begin{array}{l}\text { High modulus } \\
\text { carbon }\end{array}$} & 1760 & 903 & 2700 & 0.3 \\
\hline & 1760 & 647 & 2911 & 0.45 \\
\hline \multicolumn{5}{|c|}{ Resins } \\
\hline Polyester & 1100 & $2.1-3.5$ & $42-100$ & 5.0 \\
\hline Epoxy & 1200 & $2.5-3.5$ & $24-28$ & - \\
\hline
\end{tabular}

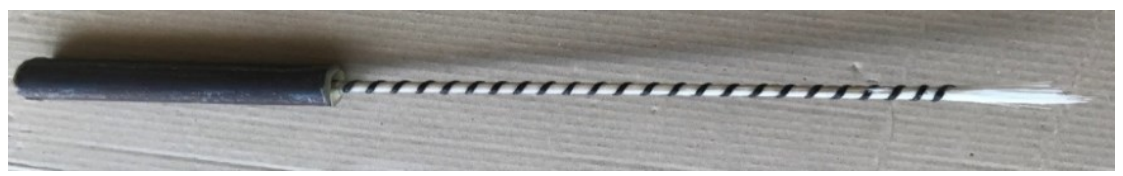

Fig. 2 - The nature of the destruction of samples of fiberglass reinforcement during testing in accordance with GOST 12004 [5]

The results of processing the experimental data by the authors of the article and presented in the technical recommendations TR 013-1-04 are shown in Table 2. The following values of the mechanical properties indicators were taken in the estimated calculations: elastic moduli of glass fibers - $73 \mathrm{GPa}$; basalt fibers - $83 \mathrm{GPa}$; polymer binder $-3.5 \mathrm{GPa}$.

From the data obtained, it also follows that fiberglass and basalt-plastic reinforcement does not fully utilize the strength of the fibers. For example, for a composite based on glass fibers of type $\mathrm{E}$ (modulus of elasticity $73,000 \mathrm{MPa}$ ) and epoxy resin $(\mathrm{E}=3500 \mathrm{MPa})$, the deformation at break is $2,3 \%$. The calculated structural and mechanical assessment gives the expected strength of the composite:

$$
\sigma_{c t}=\varepsilon_{b m}\left(E_{f} \theta_{f}+E_{m} \theta_{m}\right)=0,023(73000 \cdot 0,71+3500 \cdot 0,29)=1215 M P a
$$

Stresses in a glass fiber at the moment of destruction of the composite:

$$
\sigma_{f t}=\varepsilon_{b m} E_{f}=0,023 \cdot 73000=1679 M P a
$$

Similarly for basalt fiber:

$$
\sigma_{c t}=\varepsilon_{b m}\left(E_{f} \theta_{f}+E_{m} \theta_{m}\right)=0,025(83000 \cdot 0,71+3500 \cdot 0,29)=1499 M P a
$$


Table 2. Results of structural and mechanical analysis of composite reinforcement presented in technical recommendations TR 013-1-04

\begin{tabular}{|c|c|c|c|c|c|c|}
\hline \multirow[t]{2}{*}{ Parameter name } & \multicolumn{3}{|c|}{$\begin{array}{c}\text { Fiberglass } \\
\text { reinforcement with a } \\
\text { nominal diameter, mm }\end{array}$} & \multicolumn{3}{|c|}{$\begin{array}{l}\text { Basalt plastic reinforcement } \\
\text { with nominal diameter, } \mathrm{mm}\end{array}$} \\
\hline & 5 & 8 & 10 & 5 & 8 & 10 \\
\hline $\begin{array}{l}\text { Measured ultimate tensile } \\
\text { strength, } \mathrm{MPa}\end{array}$ & 1200 & 1040 & 880 & 1500 & 1300 & 1100 \\
\hline Elongation at break, $\%$ & 2.3 & 2.3 & 2.3 & 2.5 & 2.5 & 2.5 \\
\hline Elastic modulus, MPa & 52800 & 41360 & 41360 & 60000 & 47000 & 47000 \\
\hline $\begin{array}{l}\text { Calculated volumetric } \\
\text { content of fibers, } \%\end{array}$ & 71 & 55 & 55 & 71 & 55 & 55 \\
\hline $\begin{array}{l}\text { Calculated (predicted) } \\
\text { tensile strength by the } \\
\text { second } \\
\begin{array}{ll}\text { mechanism, } \mathrm{MPa} \\
\text { macture }\end{array} \\
\end{array}$ & 1215 & 960 & 960 & 1499 & 1175 & 1175 \\
\hline
\end{tabular}

Taking into account that the strength of glass fibers is $3300 \mathrm{MPa}$ it follows from the data obtained that only about $51 \%$ of the strength of the fibers is realized in the composite by the time of fracture. The above calculation is approximate since the modulus of elasticity of the resin depends on the degree of its curing and the nature of the packing of molecules in the layer near the surface to the fibers. However the contribution of this parameter to the strength of the composite is insignificant. The main contribution is made by the fracture deformation of the composite (and the accuracy of its determination).

When using formula (2) one should also take into account the scale factor which consists in a decrease in the measured strength of the composite reinforcement with an increase in its diameter. However in this case it is necessary to take into account the imperfection of the test methods. In particular during tensile tests in accordance with GOST 12004 the measurement results are significantly influenced by the stress concentration near the clamps of the clamps due to the absence of a transition zone from the clamps to the sample rod.

The performed structural and mechanical analysis of the scale factor of stress concentration during tensile tests of construction composite reinforcement analysis showed that the radial and tangential stresses in the reinforcement bar are equal to each other and coincide in magnitude with the contact pressure P. Displacements $\delta$ (Figure 2c) linearly increase from the bar axis to its periphery and are proportional to the diameter of the rod. The greatest movement (and fiber bending) is observed in the outer layers. This leads to the effect of stress concentration causing fracture of the samples near the anchor sleeve, which is confirmed by the experimental data of the authors [5] and other researchers [27].

An additional confirming factor is that when using an anchorage connection of a modified structure, which helps to minimize the effect of stress concentration, the destruction of the rod by delamination of the binder occurs not near the anchor sleeves, but along its entire length (Figure 3) [28]. At the same time, the absence of a scale factor of the decrease in strength with an increase in the diameter of the samples is shown, which occurs when using conventional clamps.

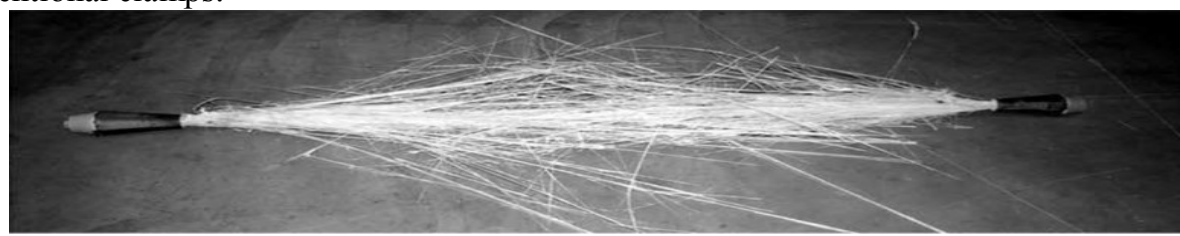


Fig. 3 - General view of the samples after the destruction of fiberglass reinforcement in special clamps, minimizing the scale effect of stress concentration [28]

Conclusions. The results of the performed structural and mechanical analysis indicate a significant effect of the polymer binder technological shrinkage on the fracture mechanism and strength at break of construction composite reinforcement.

1. In contrast to composites based on carbon fibers, for which the mechanism of initial fiber destruction with the subsequent destruction of the entire rod dominates in composites based on glass and basalt fibers the destruction mechanism prevails through the exhaustion of the strength of the binder prestressed by shrinkage stresses and delamination with the formation of a "whisk" made of reinforcing fibers.

2. The shrinkage of the polymer material in the anchor sleeve is accompanied by the appearance of a stress-strain state of the type of interference fit and stress concentration, leading to the destruction of the resin and the reinforcement bar near the concentrator, thereby contributing to a decrease in the value of the measured strength value in comparison with the scheme without a stress concentrator

\section{References}

1. M. Yu. Oshchepkov. Union of Science and Production in the Belarusian Composites Industry. 2, $34-41$ (2018)

2. E. Ya. Sadin. Anchoring in concrete of fiberglass reinforcement produced in the Republic of Belarus 3, 68 - 71 (2016)

3. V. V. Tur. Reinforced Concrete Structure. Basis of Design. (2018)

4. V. G. Barsukov, A.R. Volik, A.A. Maruk. Influence of reinforcement made of composite materials on the position of the neutral layer during bending of asymmetrically reinforced concrete beams Vol. 9, № 1,. 117 - 125 (2019)

5. A. R. Volik, S. A. Sazon, K. Yu. Churilo. Peculiarities of tensile tests of composite reinforcement Series 6 Technique, Vol 10, № 1, 110 - 118 (2020)

6. A. R. Volik, S. A. Sazon Experience and current trends in the production of construction composite reinforcement Series 6- Technique, Vol. 11. № 1. 133-141 (2021)

7. V. F. Stepanova, A.Yu. Stepanov, E.P. Zhirkov. Composite polymer reinforcement (2013)

8. V. F. Stepanova, D. A. Ilyin, A. V. Buchkin. Hybrid composite reinforcement with increased modulus of elasticity. Natural and technical sciences, , No. 9-10, 435-437 (2014)

9. Ya. A. Pronozin, V. F. Bai, Yu. V. Zazulya, R. V. Melnikov. Application of nonmetallic materials as the main reinforcement of concrete bending elements, 7, $60-61$. (2009)

10. Yi. Cui, Moe M. S. Cheung, B. Noruziaan, S. Lee, Jie Tao Development of ductile composite reinforcement bars for concrete structures, 1509 - 1518 (2008)

11. F. Matthews. Composite Materials: Mechanics and Technology, (2004)

12. O. Chaallal, B. Benmokrane Fiber-reinforced plastic rebars for concrete applications, 245 - 252 (1996)

13. H. He, K. Li, F. Gao Improvement of the bonding between carbon fibers and an epoxy matrix using a simple sizing process with a novolac resin. , 87 - 92 (2016).

14. F. Micelli, A. Nanni, Durability of FRP rods for concrete structures. Constr Build Mater 18, 491 - 503. (2004) 
15. M. G. Bader, P. W. Manders The strength of hybrid glass/carbon fiber composites, part 1: failure strain enhancement and failure mode. 16, 2233 - 2245. (1981)

16. C. E. Bakis, A. Nanni, J. A. Terosky Self-monitoring, pseudo-ductile, hybrid FRP reinforcement rods for concrete applications. 61, 815 - 823 (2001)

17. A. R. Bunsell, B. Harris Hybrid carbon and glass fiber composites. Composites 5, pp. $157-164$ (1974)

18. G. Kretsis A Review of the tensile, compressive, flexural, and shear properties of hybrid fiber-reinforced plastics. Composites 18, 13 - 23. (1987)

19. A. Nanni, J. S. Nenniger, K. D. Ash, J. Liu. Experimental bond behavior of hybrid rods for concrete reinforcement. 339 - 353 (1997)

20. A. Nanni, J. Liu. Modeling of bond behavior of hybrid rods for concrete reinforcement. 5 (4), 355 - 368. (1997)

21. V. G. Barsukov, A. R. Volik, S. A. Sazon. Structural and Mechanical Aspect of Composite Reinforcement Strength (ICBTE 2020) October 29-30, 2020, Brest, Belarus E3S Web Conf. Vol. 212, (2020)

22. B. Jarek, A. Kubik Application of glass fiber reinforcing bars (GFRP) in construction, 12, $21-26(2015)$

23. V. M. Kenko. Nonmetallic materials and methods of their processing, (1998)

24. V. G. Barsukov, Yu. M. Dal, R. A. Lubovskaya, V. V. Barsukov. Calculated estimation of thermoelastic stresses in the vicinity of fibrous and dispersed fillers in composites based on fluoroplastics Series 6 Technique, Vol. №2 (204) 6 - 13 (2015)

25. Influence of chemical shrinkage of the binder during curing on the formation of residual stresses in cylindrical shells made of composite . Release.31 67 - 72 (2016)

26. B. V. Minenkov, Strength of plastic parts, (1977)

27. S. Dong-Woo, K. Park, Y. You, S. Lee. Experimental investigation for tensile performance of FFRP-steel hybridized rebar Advances in materials science and engineering, (2016)

28. D. A. Hernandez, C. A. Soufen, M. O. Orlandi. Carbon Fiber Reinforced Polymer and Epoxy Adhesive Tensile Test Failure Analysis Using Scanning Electron Microscopy Vol.20 No.4 (2017)

29. V. Carvelli, G. Fava, M. Pisani. Anchor system for tension testing of large diameter GFRP bars 2009, $344-349$ (2009) 